\title{
Análise textual do conteúdo em websites e redes sociais com uma abordagem sistêmica para a Gestão Estratégica do Design na criação de nomes de marcas: um estudo de caso.
}

\section{Berlato-Fontoura, Larissa a, Castro-Gómez, Francisco b' Gonçalves-de Figueiredo, Luiz Fernando ${ }^{c}$; Merino- Schmidt, Giselle, ${ }^{d}$ \& Merino-Díaz, Eugenio Andrés ${ }^{e}$,}

${ }^{a}$ Mestranda - Estudante (Núcleo de Abordage Sistêmica do Design, Universidade Federal de Santa Catarina).lari.berlato@gmail.com

${ }^{\mathrm{b}}$ Doutorando, - Estudante (Núcleo de Abordage Sistêmica do Design, Universidade Federal de Santa Catarina). francisco.gomez.castro1@gmail.com

${ }^{\text {e}}$ Pós-doutor - Professor (Núcleo de Abordage Sistêmica do Design, Universidade Federal de Santa Catarina).1ffigueiredo2009@gmail.com

${ }^{\text {e} P o ́ s-d o u t o r a ~-~ P r o f e s s o r a ~(N u ́ c l e o ~ d e ~ G e s t a ̃ o ~ d e ~ D e s i g n, ~ U n i v e r s i d a d e ~ F e d e r a l ~ d e ~ S a n t a ~ C a t a r i n a) . ~}$ gisellemerino@gmail.com

ePós-doutor - Professor (Núcleo de Gestão de Design, Universidade Federal de Santa Catarina). eugenio.merino@ufsc.br

\section{Resumo}

$O$ interesse em inovação em Florianópolis durante o mês de outubro é observável pelo elevado número de eventos que acontecem, podendo ser agrupados em três dimensões: tecnologia, ambiental e social. Embora sejam dimensões diferentes, todas procuram a reflexão, o aprendizado e o planejamento organizado ligado à inovação. Entretanto, esses eventos são organizados e comunicados individualmente, criando situações de concorrência direta entre eles. O desenvolvimento de uma imagem local, assim como salientar as características culturais e experienciais do lugar, resulta em especial interesse na gestão estratégica comunicacional da cidade. O objetivo desse artigo é levantar características e atributos para a criação de um nome e valores de marca que considere todos os agentes envolvidos nos eventos de inovação em Florianópolis. A perspectiva da pesquisa foi baseada na teoria fundamentada com uma abordagem sistêmica, e na sua classificação: aplicada por sua natureza, qualitativa pela forma de abordagem, exploratória por seus objetivos e um estudo de casos pelos procedimentos técnicos. Os objetos pesquisados foram plataformas das redes sociais dos eventos do estudo. Os métodos de análise foram: análise textual do conteúdo por meio de nuvens de palavras dos conteúdos das plataformas 
das redes sociais de estudo; e avaliação e diagnose de palavras por técnicas de naming.

Palavras-chave: Abordagem Sistêmica. Naming. Gestão de Design. Cidades Criativas. Design sistêmico.

\begin{abstract}
The interest in innovation in Florianópolis during the month of October is observable by the high number of events that happen, being able to be grouped in three dimensions: technology, environmental and social. Although they are different dimensions, they all seek reflection, learning and organized planning linked to innovation. However, these events are organized and communicated individually, creating situations of direct competition between them. The development of a local image, as well as highlighting the cultural and experiential characteristics of the place, results in special interest in the strategic communication management of the city. The objective of this article is to raise characteristics and attributes for the creation of a name and brand values that considers all the agents involved in the innovation events in Florianópolis. The research perspective was based on theory based on a systemic approach, and its classification: applied by its nature, qualitative by the way of approach, exploratory by its objectives and a case study by technical procedures. The objects surveyed were platforms of social networks of study events. The methods of analysis were: textual analysis of the content by means of word clouds of the contents of the platforms of the social networks of study; and evaluation and diagnosis of words by naming techniques.
\end{abstract}

Key words: Systemic Approach, Naming, Design Management, Systemic Design, Creative Cities.

\title{
1. Introdução
}

Florianópolis tem chamado a atenção não somente pelas suas belezas naturais e seu potencial turístico de lazer, mas também tem se destacado na área de turismo de eventos, 
sendo considerada o quarto destino internacional de eventos no Brasil (ICCA, 2017). Salienta-se também a alta qualidade dos recursos humanos; a grande quantidade de instituições de ensino superior, de incubadoras, empresas de tecnologia e parques tecnológicos.

De acordo com Tenan (2002) a captação e a promoção de eventos vem sendo considerada a atividade de maior retorno econômico e social para o país e a cidade que os sedia, citando como benefícios dos eventos o equilíbrio da oferta e da demanda, possibilidade de prever melhor a demanda, menor investimento na promoção do local, enriquecimento da vida cultural da cidade, mídia espontânea, maior tempo de permanência do turista, geração e retorno de impostos. Em alguns estados, o turismo de negócios corresponde a $40 \%$ do fluxo global de turistas. A principal vantagem desse segmento é o seu potencial gerador de renda e de lucratividade. O segmento de eventos e negócios remunera de três a quatro vezes mais que o lazer e já responde pela maior fatia da receita global do setor, estimada em 3 bilhões de reais por ano (Melo Neto, 2001).

O interesse em inovação na cidade de Florianópolis durante o mês de outubro é observável pelo elevado número de eventos que acontecem, podendo ser agrupados em três dimensões: tecnologia, ambiental e social. Embora sejam dimensões diferentes, todas procuram a reflexão, o aprendizado e o planejamento organizado ligado à inovação. Na perspectiva de Jonash \& Sommerlatte (2000), inovar é um processo de alavancar a criatividade para gerar valor de novas maneiras através de novos produtos, serviços e negócios, o autor associa a inovação com a atividade criativa, que é uma área afim ao design. Entretanto, esses eventos estão sendo organizados e comunicados individualmente, muitas vezes ocasionando problemas de audiência e sustentabilidade financeira.

O objetivo dessa pesquisa é levantar características e atributos para a criação de um nome e valores de marca que considere todos os agentes envolvidos nos eventos de inovação em Florianópolis.

\section{Procedimentos Metodológicos}

A perspectiva da pesquisa foi baseada na teoria fundamentada com uma abordagem sistêmica, e na sua classificação: aplicada por sua natureza, qualitativa pela forma de abordagem, exploratória por seus objetivos e um estudo de casos pelos procedimentos técnicos.

Em uma primeira etapa foram realizadas uma revisão literária e uma análise acerca dos pressupostos teóricos que balizam as temáticas que envolvem abordagem sistêmica, naming, gestão de Design, cidades criativas e Design sistêmico. O delineamento desse 
estudo foi feito por meio de uma pesquisa bibliográfica em periódicos, artigos científicos e livros.

Na segunda etapa foi realizada a busca das palavras mais representativas em um processo sistêmico-relacional nas mensagens de conteúdo textual entre emissores e receptores tendo como objetos pesquisados os perfis da rede social Facebook ${ }^{1}$, no formato de página de fãs (Semana do Lixo Zero 2016 ${ }^{2}$ ) ou no formato de evento (RD Summit $2016^{3}$ e Social Good $2016^{4}$ ), modalidades oferecidas pela plataforma social. O tipo de amostra foi intencional: por intensidade e conveniência (Fragoso, Recuero \& Amaral, 2011).

Posteriormente, o levantamento das palavras mais representativas de cada um dos eventos de estudo foi avaliado pelos critérios selecionados de técnicas de naming. Os resultados obtidos propõem um conjunto de palavras avaliadas pelo grau de adequação ao conceito de inovação desenvolvido na cidade de Florianópolis e organizados nas dimensões: social, ambiental e tecnológico mapeadas.

O método aqui apresentado simplifica o processo de criação de nomes de marcas ao trabalhar com grupos empresariais ou de instituições com atividades diferentes, facilitando o processo criativo em termos de eficiência e praticidade; tendo como foco principal a análise de conteúdo textual nas plataformas digitais e a apresentação das alternativas mais adequadas, considerando todos os agentes envolvidos no processo comunicacional.

\section{Fundamentação teórica}

\subsection{A Abordagem Sistêmica, o processo de comunicação e a interatividade.}

Um sistema é um complexo de elementos em interação, sendo necessário estudar não somente partes e processos isoladamente, mas também resolver os problemas encontrados na organização e na ordem que os unifica, resultante da interação dinâmica das partes (Bertalanffy, 1977). A concepção sistêmica observa o mundo em termos de relações e de integração; sendo os sistemas totalidades integradas - onde o todo é sempre diferente da soma de suas partes (Capra, 1982).

\footnotetext{
${ }^{1}$ Facebook: https://www.facebook.com/

${ }^{2}$ Semana do Lixo Zero 2016:

https://www.facebook.com/semanalixozeroflorianopolis/?hc_ref=PAGES_TIMELINE\&fref=nf

${ }^{3}$ RD Summit 2016: https://www.facebook.com/events/261654227522117/

${ }^{4}$ Social Good Brasil 2016: https://www.facebook.com/events/1757434787820323/?active_tab=about
} 


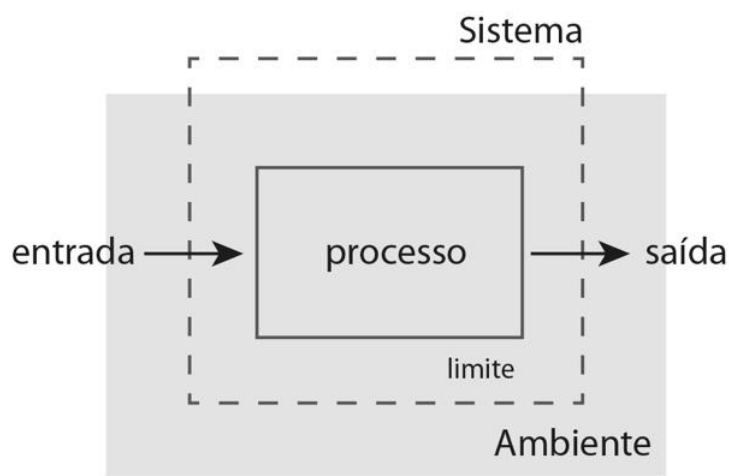

Fig. 1: Modelo processo sistêmico (Bertalanffy, 1977)

O Pensamento Sistêmico está interessado nas características essenciais do todo integrado e dinâmico, características essas que não estão em absoluto nas partes, mas nos relacionamentos dinâmicos entre elas, entre elas e o todo, e entre o todo e outros todos. No pensamento sistêmico utiliza-se o pensamento em rede, concentra-se nos padrões e nas formas, implica numa mudança da ênfase da mensuração quantitativa dos objetos para uma postura de mapeamento e visualização de contextos, relações, formas e padrões. Ao observar um problema como um sistema, sendo formado por elementos, com relações, objetivos e um meio-ambiente, muitas soluções podem surgir (Andrade, Seleme, Rodrigues \& Souto, 2006).

No referido à comunicação, o modelo básico de comunicação segundo Bierman e Drebin (1979) em sentido amplo é constituído dos seguintes elementos: (1) Uma fonte de informação que produz uma mensagem, ou sequência de mensagens a serem comunicadas ao receptor; (2) Um transmissor que opera a mensagem de alguma forma para produzir um sinal passível de ser transmitido através do canal; (3) Canal, que é o meio utilizado para se transmitir o sinal; (4) Receptor, que realiza a operação inversa do transmissor, reconstruindo a mensagem a partir do sinal; e (5) Destino, que é a pessoa para a qual a mensagem é dirigida.

Em um processo de comunicação, o problema semântico diz respeito à distância existente entre o significado que um emissor pretende transmitir através de determinado código e a interpretação que o receptor atribui à mensagem recebida. Para minimizar esse problema, é necessário utilizar códigos linguísticos que permitam a melhor aproximação possível entre significados pretendidos e alcançados (Berlo, 1999). Dessa forma, nenhum ato de comunicação está previamente determinado, apenas uma parte. 
A instância é compreendida como uma entidade composta de vários tipos de atores. A instância de recepção, podemos dizer que se desenvolve em duas grandes categorias: destinatário-alvo e o receptor-público; o primeiro é um conjunto impreciso de sujeitos que podem se associar a valores ético-sociais propostos pela instância de produção que por sua vez se subdividem em duas tipologias: alvo intelectivo e alvo afetivo. Onde o alvo intelectivo será aquele sujeito capaz de avaliar de modo racional a notícia, e por enquanto o alvo afetivo é aquele que se acredita não avaliar de modo racional, mas sim de modo inconsciente através da ordem emocional. Por outro lado, a segunda grande categoria da instância de recepção é do receptor-público que é a região que é coberta pelas pesquisas e estudos de comportamento do consumidor (Charaudeau, 2006).

O estudo da interação mediada por computador, assim como a interatividade entre os agentes envolvidos estará baseada no conceito sistêmico-relacional dos textos escolhidos na amostragem. Considerando-se em torno de três binômios: participação-intervenção, bidirecionalidade-hibridação e potencialidade-permutabilidade (Silva, 2000).

A perspectiva sistêmica desta pesquisa se dá sob o olhar na comunicação entre os eventos estudados e seus públicos-alvo, a partir de uma análise do conteúdo textual da rede social Facebook e a relação que se estabelece entre os eventos estudados e seus públicos correspondentes. Para tanto, analisa prioritariamente a produção de conteúdo textual, a recepção e a interação entre os agentes envolvidos dentro deste canal, com o intuito de gerar informações que contribuam no processo de naming.

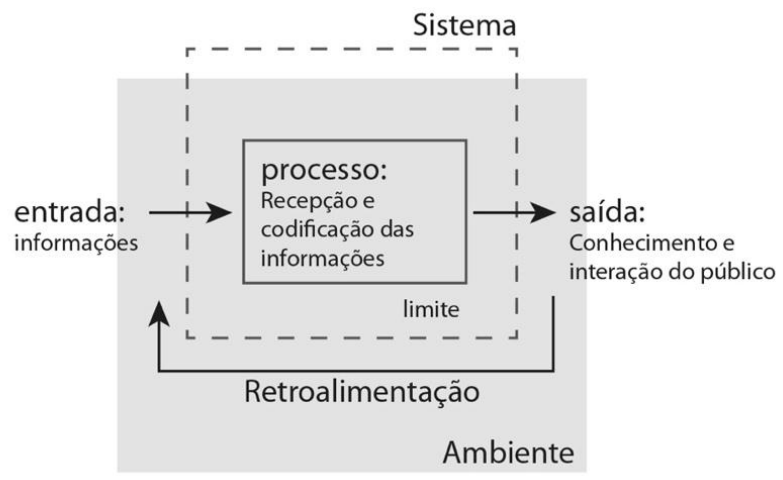

Fig 2: Esquemático de um sistema de comunicação

\subsection{Gestão do Design, a Inovação e Economia Criativa}

A Gestão do Design surgiu, ainda que voltada para a diferenciação, da percepção de que a atividade de Design pode contribuir para com a orientação empresarial através de seu 
caráter projetual, no que diz respeito ao arranjo de fatores que determinem um trajeto inovador rumo a um objetivo (Martins \& Merino, 2011). A relação entre Design, gestão e inovação tem se desenvolvido e estreitado no contexto contemporâneo de mudanças aceleradas. A inovação baseada no Design, implica a gestão do relacionamento entre o Design e a inovação, sendo a inovação determinada pelas necessidades dos usuários (Best, 2012).

A Gestão do Design pode estar presente nos níveis estratégico, tático ou operacional, no estabelecer de objetivos de longo-prazo e em tomadas de decisão do dia-a-dia. O Design é uma função, um recurso, e um modo de pensar, no contexto organizacional, que pode estar presente no pensamento estratégico, no desenvolvimento de processos, e crucialmente, na implementação de projetos, sistemas e serviços (Best, 2012).

O conceito de Economia Criativa teve origem no termo Indústria Criativa, inspirado no projeto Creative Nation

ia e talento individual (ONU, 2010).

A abordagem das Nações Unidas (2010) para as indústrias criativas se apoia em ampliar o conceito de "criatividade" passando-o de atividades que possuem um sólido componente artístico para "qualquer atividade econômica que produza produtos simbólicos intensamente dependentes da propriedade intelectual, visando o maior mercado possível" 


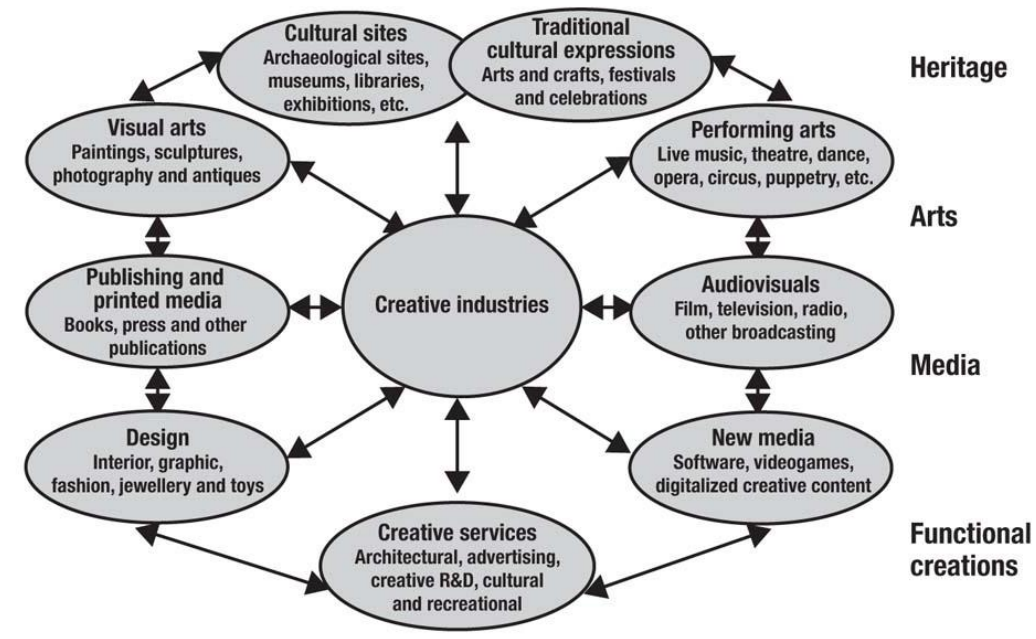

Fig 4: Modelo de Indústrias Criativas (ONU, 2010)

De acordo com Howkins (2002) a economia criativa se assenta sobre a relação entre a criatividade, o simbólico e a economia. Assim, economia criativa é o conjunto de atividades econômicas que dependem do conteúdo simbólico - nele incluído a criatividade como fator mais expressivo para a produção de bens e serviços. Segundo Landry (2000) atualmente muitas das cidades do mundo enfrentam períodos de transição em grande parte provocada pelo vigor de uma nova globalização.

Firjan

abaixo. 


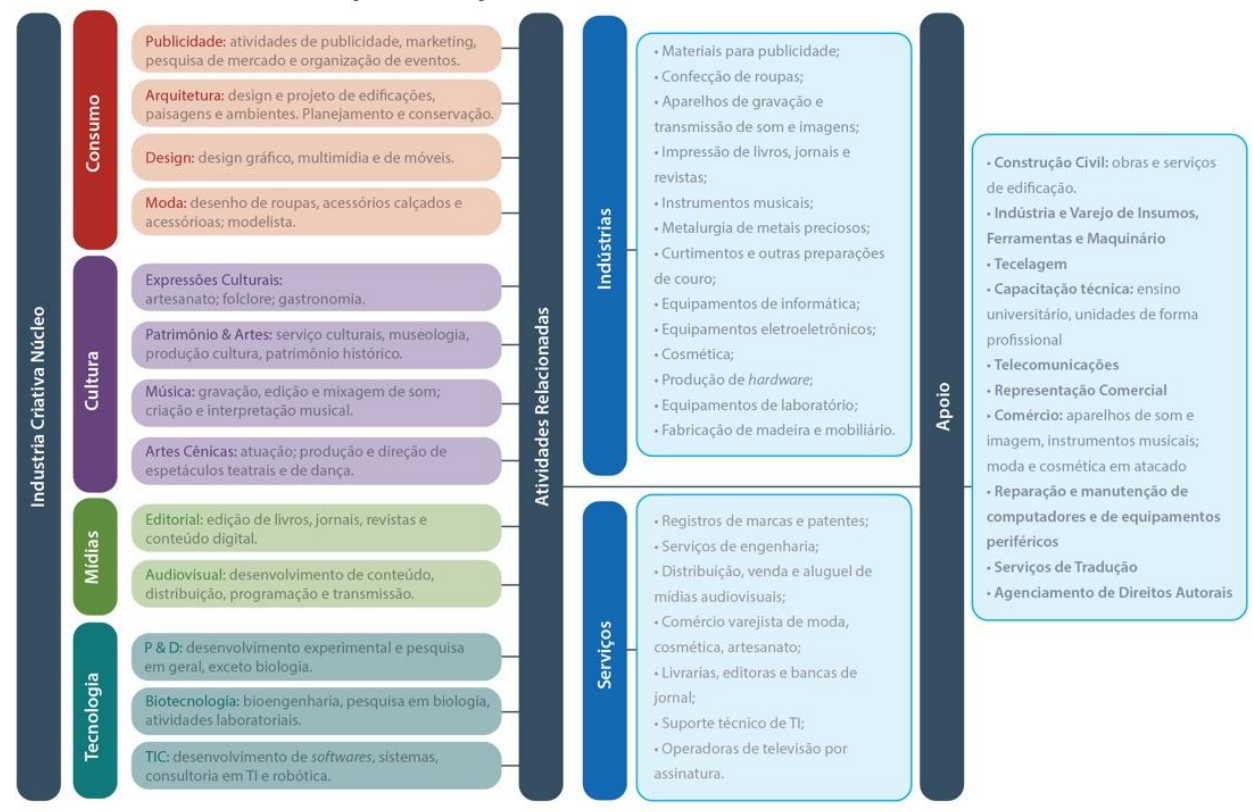

Fig 5: Fluxograma da cadeia da Indústria Criativa no Brasil (Firjan, 2016)

O relatório do Mapeamento das Indústrias Criativas no Brasil apresenta uma estimativa de do PIB Criativo, em ao PIB Total (2004-2013), que passou de 2,09\%, em 2004, para 2,60\%, em 2013 (FIRJAN, 2016).

\subsubsection{As Cidades Criativas e Florianópolis como cidade criativa}

As cidades criativas tendem a ser construídas sob uma sólida infraestrutura social e cultural, com altas concentrações de emprego criativo, -de-obra altamente qualificada e e cultura empreendedora, aplicada a fins econômicos e sociais. Tratrar uma cidade como criativa significa estabelecer uma segunda de ligadas criatividade e urbana, apoiada em uma atitude tolerante, que valorize a diversidade social e cultural, num conjunto com vistas a fomentar a capacidade de e de desenvolvimento de produtos , e atrair e fixar de talentos que contribuam para o desenvolvimento da cidade, os chamados "membros da classe criativa" (Florida, 2011). Seul, Barcelona, Berlim, Austin, Bogotá, Melbourne e Londres são alguns dos exemplos de cidades criativas.

A Rede de Cidades Criativas da UNESCO surgiu em 2004 e possuí 116 membros divididos nas seguintes categorias: artesanato; design; cinema, literatura; multimídia, música e 
gastronomia, nesta última categoria tendo

(SC, Brasil) como integrante (UNESCO, 2017).

Florianópolis, a capital de Santa Catarina, é a quarta cidade que mais recebe eventos internacionais do Brasil (ICCA, 2017), recebeu 16 eventos internacionais em 2016, seis a mais do que no ano anterior e subiu uma posição, comparado ao ranking do ano anterior. $\mathrm{O}$ interesse em inovação na cidade durante o mês de outubro é observável pelo elevado número de eventos que acontecem, podendo ser agrupados em três dimensões: tecnologia, ambiental e social e sendo representados mais significativamente pelos seguintes eventos: RD Summit, Semana Lixo Zero e Social Good Brasil.

O RD Summit é considerado o maior evento de marketing digital e vendas do Brasil e o mais completo da América Latina; têm como objetivo oferecer conteúdo relevante e experiências de sucesso sobre Inbound Marketing, Marketing de conteúdo e Marketing digital. Em 2016, recebeu mais de 5.500 pessoas.

A Semana Lixo Zero é uma plataforma mobilizadora que tem como objetivo conscientizar, empoderar e trazer soluções para que a meta lixo zero seja alcançada. Em 2014, abrangeu 2 países, 4 estados e 11 cidades participantes, totalizando mais de 400 eventos, atingindo mais de 22 mil pessoas.

O Festival Social Good Brasil faz parte de um movimento internacional global baseado no conceito de usar a tecnologia e o pensamento inovador para resolver problemas sociais. $\mathrm{O}$ evento tem como objetivo impulsionar o protagonismo das pessoas, oferecendo ambientes de conexão e troca, suporte e apoio. Em 2016, reuniu cerca de 1000 pessoas presencialmente e mais de 60 mil pessoas acompanharam o streaming e os vídeos disponíveis.

Embora sejam dimensões diferentes, todas procuram a reflexão, o aprendizado e o planejamento organizado ligado à inovação. Entretanto, esses eventos são organizados e comunicados individualmente, criando situações de concorrência direta entre eles. Em alguns casos, essa concorrência gera problemas na sustentabilidade financeira, por falta de participantes, ou apenas repetição dos participantes, por falta de visibilidade.

A colaboração entre os eventos pode potencializar o sucesso dos mesmos e gerar benefícios para a cidade. Dessa forma, sugere-se a criação de um evento único que agregue os eventos que ocorrem no mês de outubro em Florianópolis relacionados à inovação.

\subsection{Marca e Naming}

Uma marca pode ser um nome, termo, símbolo, desenho ou uma combinação desses elementos a fim identificar os bens ou serviços de uma empresa ou grupo de empresas para diferenciá-los dos da concorrência (Kotler, 2000). O valor de uma marca vem de sua 
habilidade em ganhar um significado exclusivo, destacado e positivo na mente dos clientes (Kapferer, 1992).

O nome é um símbolo complexo que tem o potencial de representar muitas ideias e atributos associados ao produto que representa (Leone, 1981). O nome da marca é o componente de uma marca, que pode ser falado ou verbalizado (Anderson e Bennett, 1988). O nome é o primeiro e mais usado elemento de comunicação de uma marca, servindo como um ponto central, sendo o responsável por acionar as lembranças positivas ou negativas de uma marca (Kollmann, 2007).

A criação deste nome, dá-se o nome de naming, uma das etapas principais no processo criativo de uma marca. A definição de um nome para produto ou serviço é tão crítica, que alguns autores acreditam ser uma das mais importantes decisões de marketing (Landler; Schiller \& Therrien, 1991).

De acordo com Wheeler (2012), não existe um método único no processo de criação de nomes de marcas. Todos os passos ou métodos sugeridos por autores que abordam o processo de naming não desconsideram o fato que dar nomes é um processo rigoroso e exaustivo e que técnicas são necessárias a fim de verificar a eficácia de um nome e garantir que suas conotações sejam positivas no mercado a ser atendido. De acordo com a autora, os nomes de marca precisam ser julgados e determinados levando em conta metas, posicionamento, desempenho e disponibilidade dentro de um determinado setor, caso contrário, quando a escolha de um nome é negligenciada e o nome não é ideal, o mesmo pode se tornar um obstáculo, produzindo uma figura errônea na mente do público-alvo, dificultando a gestão estratégica do design.

O processo de naming é um trabalho multidisciplinar, que pode incluir, entre outros assuntos, estudos de linguística (estrutura da língua), bem como de simbologia profunda (significados inerentes), de significados adquiridos (associações acumuladas ao longo do tempo), de significados intrínsecos (derivações de radicais), de fonética (sons da fala) e de etologia (comportamento) (Knapp, 2002).

Os estudiosos da área reconhecem alguns critérios para desenvolvimento de um nome de marca eficiente conforme a tabela 1 : 
Tabela 1: Autores e critérios para o desenvolvimento de naming

\begin{tabular}{|c|c|}
\hline AUTORES & CRITÉRIOS PARA DESENVOLVIMENTO DE NAMING \\
\hline BERRY ET AL.(1988) & $\begin{array}{l}\text { Distinção; } \\
\text { Relevância; } \\
\text { Facilidade de memorização; } \\
\text { Flexibilidade. }\end{array}$ \\
\hline KNAPP (2002) & $\begin{array}{l}\text { Disponibilidade; } \\
\text { Possibilidade de proteção; } \\
\text { Aceitabilidade; } \\
\text { Exclusividade; } \\
\text { Credibilidade; } \\
\text { Reprodutibilidade; } \\
\text { Legibilidade; } \\
\text { Durabilidade; } \\
\text { Compatibilidade. }\end{array}$ \\
\hline AAKER (2002) & $\begin{array}{l}\text { Diferente ou incomum; } \\
\text { Chamar a atenção; } \\
\text { Despertar a curiosidade. }\end{array}$ \\
\hline MARTINS (2006) & $\begin{array}{l}\text { Sonoridade; } \\
\text { Criatividade; } \\
\text { Pertinência. }\end{array}$ \\
\hline NEUMEIER (2008) & $\begin{array}{l}\text { Distinguibilidade; } \\
\text { Brevidade; } \\
\text { Conveniência; } \\
\text { Grafia e pronúncia fáceis; } \\
\text { Agradabilidade; } \\
\text { Extensibilidade, adequação a diferentes finalidades criativas; } \\
\text { Possibilidade de proteção, aspectos legais. }\end{array}$ \\
\hline
\end{tabular}

\section{Desenvolvimento}

\subsection{Amostragem do estudo}

A construção da amostra dos sites de estudo em relação ao tipo de amostra, referente aos sites escolhidos para esse estudo, segundo Fragoso et al. (2011), foi intencional, pois procurou-se amostras representativas cujos elementos são selecionados conforme critérios 
que derivam do problema da pesquisa, das características do universo observado e das condições e métodos de observação e análise. Segundo os subtipos de amostras intencionais que propõem as autoras, a amostra do estudo pode ser caracterizada pelos seguintes subtipos: por intensidade e por critério. Por intensidade, posto que a seleção de sites favorece os elementos em que as características que interessam à pesquisa estão presentes de forma intensa ou evidente, mas que não se caracterizam como casos extremos. Localizando a observação em casos ou elementos nos quais a informação é mais densa ou fácil de verificar e colocando em foco características previamente definidas. Por outro lado, a caracterização por critério, refere-se ao fato de que foram selecionados os sites que apresentavam uma determinada característica ou critério predefinido.

\subsection{Etapas da pesquisa}

O estudo foi conduzido a partir das quatro principais etapas citadas e detalhas a seguir:

1. Escolha dos sites de pesquisa na rede social Facebook;

2. Criação das nuvens de palavras e lista das cinco palavras mais repetidas do emissor e do receptor de cada uns dos eventos de estudo;

3. Agrupamento em conceitos das técnicas de naming levantadas pelos autores e que serão consideradas na análise das palavras mais repetidas;

4. Resultados: análise propriamente dita;

5. Conclusões.

\subsubsection{Etapa 1: Escolha dos sites de pesquisa na rede social Facebook.}

A escolha dos sites de pesquisa na rede social Facebook foi realizada de acordo com a modalidade disponibilizada por cada evento e atendendo ao objetivo da análise e a pesquisa dos conteúdos textuais mais alinhados à comunicação dos eventos do estudo considerando as classificações da amostra expostas anteriormente. Os objetos pesquisados são os perfis da rede social Facebook, no formato de página de fãs no caso da Semana do Lixo Zero e no formato de evento no caso RD Summit e Social Good conforme tabela abaixo.

Tabela 2: Endereços das plataformas de estudo dos endereços no Facebook

\begin{tabular}{|l|l|}
\hline EVENTO & ENDEREÇOS NO FACEBOOK \\
\hline RD Summit 2016 & https://www.facebook.com/events/261654227522117/ \\
\hline $\begin{array}{l}\text { Festival Social Good } \\
\text { Brasil 2016 }\end{array}$ & https://www.facebook.com/events/1757434787820323/?active_tab=about \\
\hline $\begin{array}{l}\text { Semana LIXO ZERO } \\
\text { Florianópolis 2016 }\end{array}$ & https://www.facebook.com/semanalixozeroflorianopolis/?hc_ref=PAGES_TIMELINE\&fref=nf \\
\hline
\end{tabular}


4.2.2 Etapa 2: Criação das nuvens de palavras e lista das cinco palavras mais repetidas do emissor e do receptor de cada uns dos eventos de estudo.

Criação das nuvens de palavras e lista das cinco palavras mais repetidas do emissor e do receptor de cada uns dos eventos de estudo baseado nos conteúdos textuais dos endereços da tabela 2 .

\subsubsection{Etapa 3: Agrupamento em conceitos das técnicas de naming}

Conforme a tabela 3, foi realizado um agrupamento das técnicas de naming visando aplicálo nas palavras mais repetidas mapeadas nas tabelas 4,6 e 8 .

Tabela 3: Conceitos selecionados para aplicar técnicas de naming

\begin{tabular}{|c|c|}
\hline CONCEITOS & CRITÉRIOS AGRUPADOS DAS TÉCNICAS DE NAMING \\
\hline Aceitabilidade & $\begin{array}{l}\text { Aceitabilidade: não deve apresentar significados negativos em outros países e } \\
\text { línguas; conveniência; agradabilidade. }\end{array}$ \\
\hline Credibilidade & Credibilidade \\
\hline Criatividade & $\begin{array}{l}\text { Criatividade: distinção; exclusividade; diferente ou incomum; chamar a atenção; } \\
\text { despertar a curiosidade; distinguibilidade; ser inconfundivel. }\end{array}$ \\
\hline Disponibilidade & Disponibilidade: possibilidade de proteção; aspectos legais. \\
\hline Durabilidade & Durabilidade \\
\hline $\begin{array}{l}\text { Facilidade } \\
\text { memorização }\end{array}$ & Facilidade de memorização: lembrança; nomes curtos; brevidade. \\
\hline Flexibilidade & $\begin{array}{l}\text { Flexibilidade: reprodutibilidade; compatibilidade; extensibilidade, adequação a } \\
\text { diferentes finalidades criativas. }\end{array}$ \\
\hline Legibilidade & $\begin{array}{l}\text { Legibilidade: facilidade de pronúncia e de reconhecimento; grafia e pronúncia } \\
\text { fáceis. }\end{array}$ \\
\hline Relevância & $\begin{array}{l}\text { Relevância: deve dizer algo a respeito dos benefícios do produto, sugerir as } \\
\text { qualidades do produto, como uma ação ou cor; pertinência. }\end{array}$ \\
\hline Sonoridade & Sonoridade \\
\hline
\end{tabular}

\subsubsection{Etapa 4: Apresentação dos resultados e análise propriamente dita}

- Apresentação das nuvens e listas de palavras do emissor (postagens) e das respostas da audiência (comentários, feedback) do receptor de cada um dos eventos;

- Análise dos resultados para a consideração das palavras em torno da adequação: aos conceitos selecionados das técnicas de naming expostos na tabela 3, aos três binônimos: participação-intervenção, bidirecionalidade-hibridação e potencialidade-permutabilidade. (Silva, 2000) e aos significados do conceito desejado neste estudo de caso, a inovação na dimensão social, tecnológica e ambiental. 


\subsubsection{Etapa 5: Conclusões do estudo}

Na última parte deste artigo poderão ser verificadas as ligações entre as problemáticas e objetivos observados no estudo, onde são propostas novas linhas de pesquisa e considerações nas técnicas de criação de nomes de marca assim como as vantagens de uso, limitações e finalidade do método aqui proposto.

\section{Análise e Discussão de Resultados}

Os resultados aqui apresentados referem-se principalmente a dois processos de pesquisa: a apresentação dos resultados (tabelas: 4, 6 e 8) e a avaliação desses (tabelas: 5, 7 e 9).

No primeiro processo foi realizado um levantamento de dados de cada um dos eventos de estudo dos endereços apresentados na tabela 2. Nesse levantamento dos conteúdos textuais, os dados foram divididos nos agentes emissor e receptor para a posterior criação de nuvens de palavras e lista de palavras mais repetidas nos endereços mostrados na tabela 2. A criação das nuvens de palavras, assim como as listas ordenadas de palavras foram a partir da ferramenta WordArt $^{5}$ pela sua disponibilidade e acesso gratuito na rede. As listas de palavras tanto do emissor quanto do emissor estão organizadas de acordo com o maior número de repetições.

O segundo processo (tabelas 5, 7 e 9), refere-se à avaliação dos resultados (tabelas 4, 6 e 8), em particular das palavras das listas de palavras que foram avaliadas segundo os conceitos definidos na tabela 3 .

\footnotetext{
${ }^{5}$ WordArt: https://wordart.com/
} 
Tabela 4: Nuvens e lista de palavras do emissor e receptor do evento RD Summit

\begin{tabular}{|c|c|c|c|}
\hline \multicolumn{4}{|c|}{ RD Summit 2016} \\
\hline \multicolumn{2}{|c|}{$\begin{array}{l}\text { NUVEM PALAVRAS EMISSOR } \\
\text { (Postagens) }\end{array}$} & \multicolumn{2}{|c|}{$\begin{array}{l}\text { NUVEM PALAVRAS RECEPTOR } \\
\text { (Feedback, Comentários) }\end{array}$} \\
\hline & 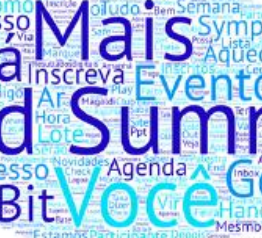 & & - serror \\
\hline \multicolumn{2}{|c|}{ LISTA DE PALAVRAS (EMISSOR) } & \multicolumn{2}{|c|}{ LISTA DE PALAVRAS (RECEPTOR) } \\
\hline 1 & Rd Summit & 1 & Evento \\
\hline 2 & Mais & 2 & Rd Summit \\
\hline 3 & 2016 & 3 & Você \\
\hline 4 & Você & 4 & Ingresso \\
\hline 5 & Gente & 5 & Mais \\
\hline
\end{tabular}

Tabela 5: Seleção de conceitos de técnicas aplicados à lista de palavras do RD Summnit 2016

\begin{tabular}{|c|c|c|c|c|c|c|c|c|c|c|}
\hline \multirow{3}{*}{ conceitos } & \multicolumn{10}{|c|}{ RD Summit 2016} \\
\hline & \multicolumn{5}{|c|}{ Emissor (mensagem) } & \multicolumn{5}{|c|}{ Receptor (feedback) } \\
\hline & $\begin{array}{l}\mathrm{Rd} \\
\text { Summit } \\
\end{array}$ & Mais & 2016 & Você & Gente & Evento & $\begin{array}{l}\mathrm{Rd} \\
\text { Summit } \\
\end{array}$ & Ingresso & Você & Mais \\
\hline Aceitabilidade & $\mathbf{x}$ & & $\mathbf{x}$ & $\mathbf{x}$ & $\mathbf{x}$ & $\mathbf{x}$ & $\mathbf{x}$ & $\mathbf{x}$ & $\mathbf{x}$ & $\mathbf{x}$ \\
\hline Credibilidade & $\mathbf{x}$ & & & & & $\mathbf{x}$ & $\mathbf{x}$ & & & \\
\hline Criatividade & & & $\mathbf{x}$ & & & & & & & \\
\hline \multicolumn{11}{|l|}{ Disponibilidade } \\
\hline \multicolumn{11}{|l|}{ Durabilidade } \\
\hline $\begin{array}{l}\text { Facilidade de } \\
\text { memorização }\end{array}$ & $\mathbf{x}$ & & $\mathbf{x}$ & & $\mathbf{x}$ & & $\mathbf{x}$ & $\mathbf{x}$ & & \\
\hline \multicolumn{11}{|l|}{ Flexibilidade } \\
\hline Legibilidade & & & & $\mathbf{x}$ & $\mathbf{x}$ & & & & & \\
\hline Relevância & $\mathbf{x}$ & & & & & & $\mathbf{x}$ & $\mathbf{x}$ & & \\
\hline Sonoridade & $\mathbf{x}$ & & & & & & $\mathbf{x}$ & $\mathbf{x}$ & & \\
\hline TOTAL & 5 & 0 & 3 & 2 & 3 & 2 & 5 & 4 & 1 & 0 \\
\hline
\end{tabular}


Berlato, Larissa Fontoura, Castro Gomez, Francisco; Gonçalves de Figueiredo, Luiz Fernando; Merino Schmidt Alves Díaz, Giselle \& Merino Díaz, Eugenio Andrés

Tabela 6: Nuvens e lista de palavras do emissor e receptor do evento Social Good Brasil 2016

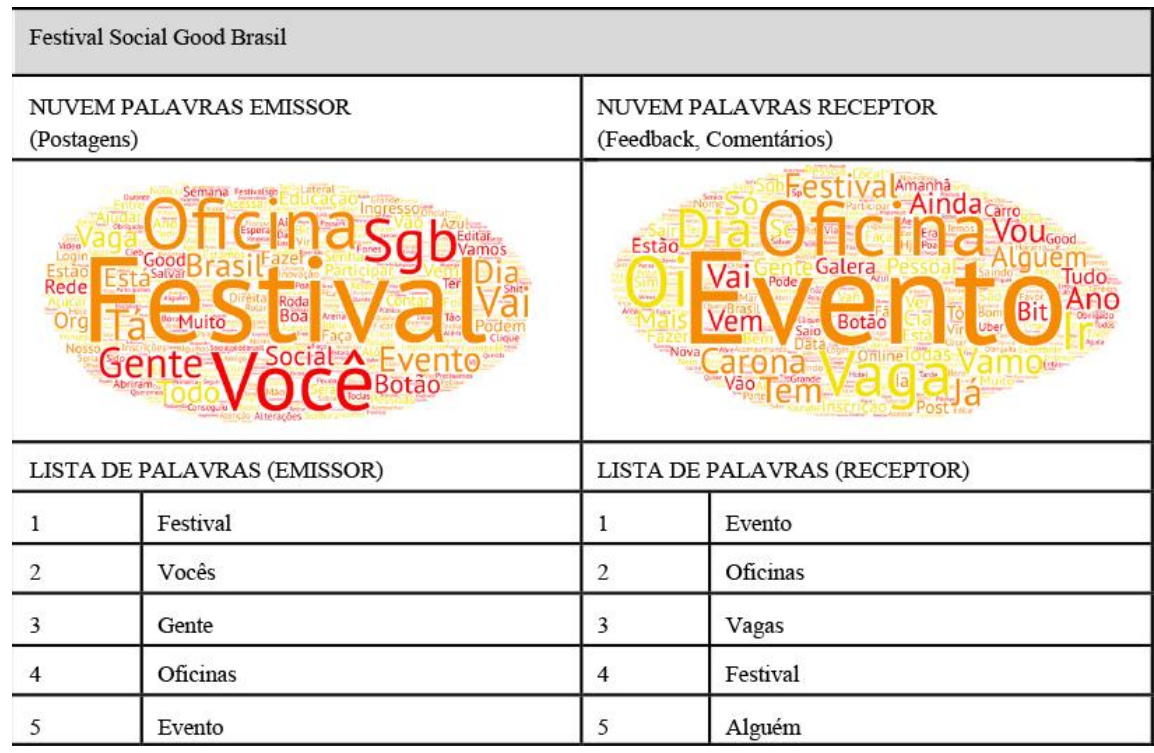

Tabela 7: Seleção de conceitos de técnicas aplicados à lista de palavras do Social Good Brasil 2016

\begin{tabular}{|c|c|c|c|c|c|c|c|c|c|c|}
\hline \multirow{3}{*}{ conceitos } & \multicolumn{10}{|c|}{ Festival Social Good Brasil } \\
\hline & \multicolumn{5}{|c|}{ Emissor (mensagem) } & \multicolumn{5}{|c|}{ Receptor (feedback) } \\
\hline & Festival & Vocês & Gente & Oficinas & Evento & Evento & Oficinas & Vagas & Festival & Alguém \\
\hline Aceitabilidade & $\mathbf{x}$ & $\mathbf{x}$ & $\mathbf{x}$ & $\mathbf{x}$ & $\mathbf{x}$ & $\mathbf{x}$ & $\mathbf{x}$ & $\mathbf{x}$ & $\mathbf{x}$ & \\
\hline Credibilidade & & & & & $\mathbf{x}$ & $\mathbf{x}$ & & & & \\
\hline Criatividade & $\mathbf{x}$ & & & & & & & & $\mathbf{x}$ & $\mathbf{x}$ \\
\hline \multicolumn{11}{|l|}{ Disponibilidade } \\
\hline \multicolumn{11}{|l|}{ Durabilidade } \\
\hline $\begin{array}{l}\text { Facilidade de } \\
\text { memorização }\end{array}$ & $\mathbf{x}$ & & & & & & & & $\mathbf{x}$ & $\mathbf{x}$ \\
\hline \multicolumn{11}{|l|}{ Flexibilidade } \\
\hline \multicolumn{11}{|l|}{ Legibilidade } \\
\hline \multicolumn{11}{|l|}{ Relevância } \\
\hline Sonoridade & $\mathbf{x}$ & & & & & & & & $\mathbf{x}$ & $\mathbf{x}$ \\
\hline TOTAL & 4 & 1 & 1 & 1 & 2 & 2 & 1 & 1 & 4 & 3 \\
\hline
\end{tabular}


Análise textual do conteúdo em websites e redes sociais com uma abordagem sistêmica para a Gestão Estratégica do Design na criação de nomes de marcas: um estudo de caso.

Tabela 8: Seleção de conceitos de técnicas aplicados à lista de palavras do Lixo Zero 2016

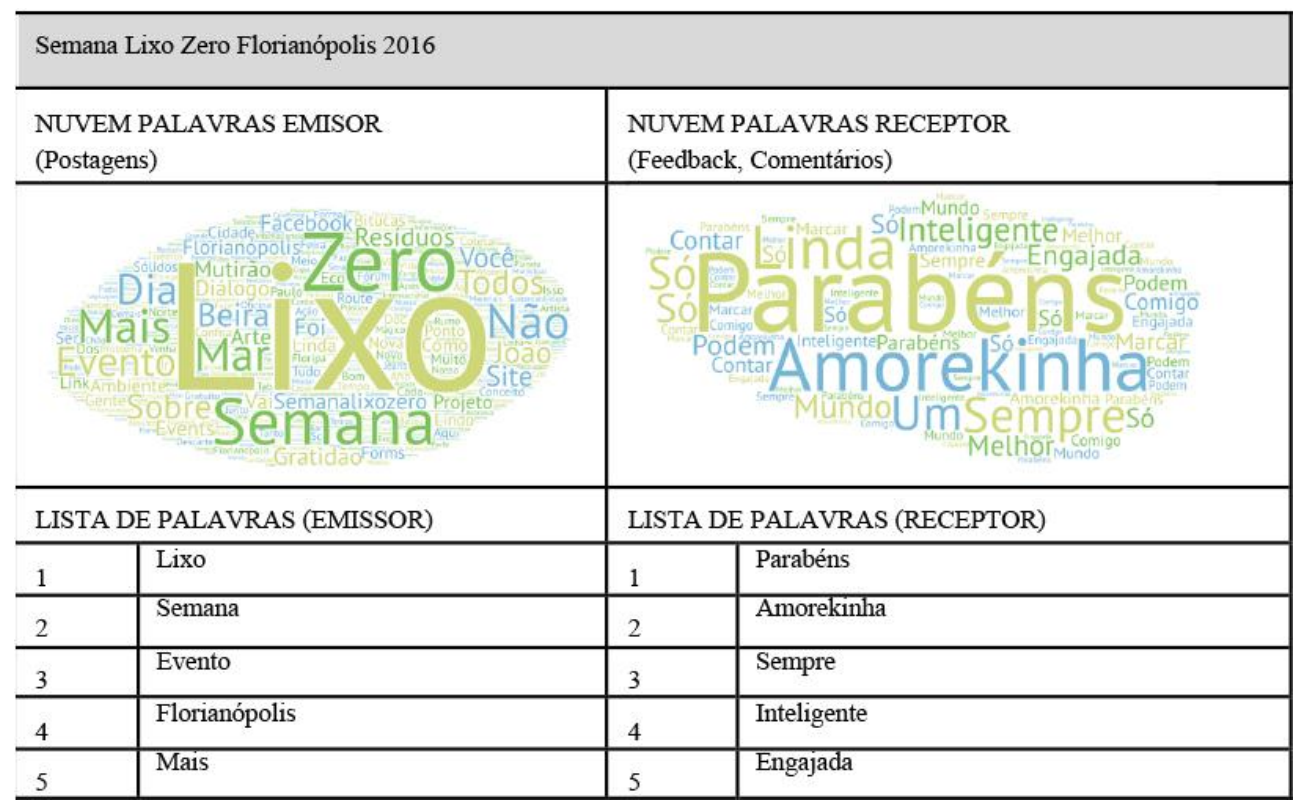

Tabela 9: Seleção de conceitos de técnicas aplicados à lista de palavras do Lixo Zero 2016

\begin{tabular}{|c|c|c|c|c|c|c|c|c|c|c|}
\hline \multirow{3}{*}{ conceitos } & \multicolumn{10}{|c|}{ Festival Lixo Zero Florianópolis 2016} \\
\hline & \multicolumn{5}{|c|}{ Emissor (mensagem) } & \multicolumn{5}{|c|}{ Receptor (feedback) } \\
\hline & Lixo & Semana & Evento & $\begin{array}{l}\text { Florianóp } \\
\text { olis }\end{array}$ & Mais & Parabéns & Amorekinha & Sempre & Inteligente & Engajad: \\
\hline Aceitabilidade & $\mathbf{x}$ & $\mathbf{x}$ & $\mathbf{X}$ & $\mathbf{x}$ & & & & & & \\
\hline Credibilidade & $\mathbf{x}$ & & $\mathbf{x}$ & $\mathbf{x}$ & & & & & & \\
\hline \multicolumn{11}{|l|}{ Criatividade } \\
\hline \multicolumn{11}{|l|}{ Disponibilidade } \\
\hline \multicolumn{11}{|l|}{ Durabilidade } \\
\hline $\begin{array}{l}\text { Facilidade de } \\
\text { memorização }\end{array}$ & $\mathbf{x}$ & $\mathbf{x}$ & & $\mathbf{x}$ & & & & & & \\
\hline Flexibilidade & $\mathbf{x}$ & & & & & & & & & \\
\hline Legibilidade & $\mathbf{x}$ & & & & & & & & & \\
\hline \multicolumn{11}{|l|}{ Relevância } \\
\hline Sonoridade & $\mathbf{x}$ & & & & & & & & & \\
\hline TOTAL & 6 & 2 & 2 & 2 & 0 & & & & & \\
\hline
\end{tabular}


As palavras com maior pontuação são identificadas como as mais adequadas para a construção do nome no processo criativo de naming de acordo com os conceitos definidos previamente. Entretanto, deve-se ainda fazer uma ligação dos significados destas palavras para com sua audiência objetiva e com o conceito de inovação, que é a linha estratégica que conecta todos os eventos.

No caso do evento Lixo Zero Florianópolis 2016, a amostragem do receptor foi descartada, posto que em termos de interatividade é insuficiente.

\section{Conclusão}

A captação e a promoção de eventos vem sendo considerada uma atividade de importante retorno econômico e social para o país e para a cidade que os sedia. $\mathrm{Na}$ cidade de Florianópolis, o interesse em inovação durante o mês de outubro é observável pelo elevado número de eventos que acontecem, podendo ser agrupados em três dimensões: tecnologia, ambiental e social. Embora sejam dimensões diferentes, todas procuram a reflexão, o aprendizado e o planejamento organizado ligado à inovação. Visando aumentar o impacto e repercussão destes eventos bem como potencializar Florianópolis como cidade criativa, sugere-se a criação de um evento que unifique as atividades e eventos ligados à inovação em torno de uma marca que traduza todos estes conceitos.

O método aqui apresentado busca simplificar o processo de criação de naming ao trabalhar com grupos empresariais ou instituições com atividades diferentes, facilitando o processo criativo em termos de eficiência, praticidade e assertividade; tendo como foco principal a análise de conteúdo textual nas plataformas digitais e a apresentação das alternativas mais adequadas, considerando todos os agentes envolvidos no processo comunicacional.

O levantamento das palavras mais representativas em um processo sistêmico-relacional em mensagens de conteúdo textual entre emissores e receptores, em uma plataforma digital de redes sociais, com a finalidade de serem posteriormente avaliadas e organizadas pelo grau de adequação aos critérios de técnicas de naming selecionadas, permite termos uma abordagem holística sobre o grau de compreensão de uma audiência mais heterogênea. Essa abordagem facilita o entendimento e conhecimento sobre todas as audiências contribuindo no processo de criação de naming com informações sobre a audiência e seu conhecimento e relacionamento com o cliente.

Esse método não pretende substituir nenhuma das etapas do processo criativo, e sim contribuir neste processo, permitindo ao designer quantificar as comunicações que o emissor institucional tem com seu receptor e vice-versa, contribuindo na assertividade 
durante o processo criativo e na justificativa das alternativas propostas, tornado o processo de aprovação menos abstrato, facilitando escolhas baseadas em argumentos sustentados.

\section{Referências}

Aaker, D. (2007). Construindo marcas fortes. Porto Alegre: Bookman.

Anderson, P. F.; Bennett, P. D. (1988). Dictionary of marketing terms. Chicago: American Marketing Association.

Andrade, A. L., Seleme, A., Rodrigues L.H. \& Souto, R. (2006). Pensamento sistêmico: caderno de campo: o desafio das mudanças sustentada nas organizações e na sociedade. Porto Alegre: Bookman.

Berlo, D. K. (1999). El proceso de la comunicación: introducción a la teoría ya la práctica. Buenos Aires: El Ateneu.

Berry, L.L., Lefkowith, E.F. \& Clark, T. (1988). “ $\quad$ w ， ? Harvard Business Review, Vol. 66, September-October, pp. 28-30.

Best, K. (2012). Fundamentos de Gestão do Design. Porto Alegre: Bookman. Tradução: André de Godoy Vieira.

Bertalanffy, L. V. (1977). Teoria geral dos sistemas. Trad. de Francisco M. Guimarães. 3.ed. Petrópolis: Vozes.

Bierman, H.; \& Drebin, A. R. (1979). Contabilidade gerencial. Rio de Janeiro: Editora Guanabara Dois.

Capra, F. (1982). Teia da vida: uma nova compreensão científica dos sistemas vivos. São Paulo: Cultrix.

Charaudeau, P. (2006). Discurso das mídias. São Paulo: Contexto.

Federação das indústrias do rio de janeiro (FIRJAN). (2016). Mapeamento da Indústria Criativa no Brasil. Recuperado de $<\mathrm{http}$ //www. rjan.org.br/economiacriativa/pages/default.aspx $>$

Florida, R. (2011). A Ascensão da Classe Criativa - e seu papel na transformação do trabalho, do lazer, da comunidade do cotidiano. Porto Alegre: L\&PM Editores.

Fragoso, S.; Recuero, R.; Amaral, A. (2011). Métodos de pesquisa para internet. Porto Alegre: Sulina, $239 \mathrm{p}$.

Howkins, J. (2002). The creative Economy - how people make money from ideas. Londres: Penguin Books.

ICCA https://www.iccaworld.org/

Jonash, R. S. \& Sommerlatte, T. (2000). The innovation premium. New York, Perseus Book. 
Kapferer, J.N. (1992). $\square$ Strategic Brand Management. London: Kogan Page.

Knapp, D. E. (2002). Brandmindset: fixando a marca. Rio de Janeiro: Qualitymark.

Kollmann, T.; Suckow, C. (2017). The corporate brand naming process in the net economy. Qualitative Market Research: an international journal, v. 10, n. 4, p. 349-361, september 11.

Kotler, P. (2000). Administração de marketing: a edição do novo milênio. São Paulo: Prentice Hall.

Landler, M; Schiller, Z; Therrien, L. (1991). "W ， ?: " Business Week, July 8, pp. 66-7.

Landry, C. (2000). The creative city: a toolkit for urban innovators. Londres: Comedia and Earthscan Publications.

Leone, R. P. (1981). $\quad$ P

et al., eds., The Changing Marketing Environment: New Theories and Applications. Chicago: American Marketing Association, pp. 197-200.

Martins, J. R. (2006). Branding: um manual para você criar, gerenciar e avaliar marcas. São Paulo: Ed. Negócio.

Martins, R. F. de F \& MERINO, E. A. D. (2011). Gestão de Design como Estratégia Organizacional. 2a. ed. Londrina: EDUEL.

Melo Neto, F.P. (2001). Criatividade em Eventos. 2.ed. São Paulo: Contexto.

Neumeier, M. (2008). The Brand Gap. O abismo da marca. Porto Alegre: Bookman.

ONU/UNDP/UNESCO. (2010) Creative economy report 2010 - creative economy: a feasible development option.

ONU/UNDP/UNESCO (2013). Creative economy report 2013 special edition.

Silva, M. (2000). Sala de aula interativa. Rio de Janeiro: Quartet.

Tenan, I. P. S. (2002). Eventos. São Paulo: Aleph.

UNESCO. (2017) Creative Cities Network. Recuperedo de <http://en.unesco.org/creativecities/creative-cities-map>

Wheeler, A. (2012). Design de identidade da marca: Guia essencial para toda a equipe de Gestão de marcas. 3. ed. Porto Alegre: Bookman. 